\title{
Ophthalmoplegia in carotid cavernous sinus fistula
}

\author{
T. J. K. LEONARD, I. F. MOSELEY, AND M. D. SANDERS \\ From the Departments of Neuro-Ophthalmology and Neuro-Radiology, National Hospital for \\ Nervous Diseases, Queen Square, London WC1
}

SUMMARY The aetiology of ophthalmoplegia in 15 patients with carotid-cavernous sinus fistula is discussed, and the clinical findings are correlated with angiographic and orbital CT appearances. After closure of the fistula the majority of patients with generalised ophthalmoplegia recovered full ocular movements rapidly, while patients with an isolated abduction weakness required much longer to return to normal. Orbital CT studies showed enlarged extraocular muscles in the patients with generalised ophthalmoplegia but muscles of normal size in those with abduction failure alone. After closure of the fistula repeat CT studies of patients with enlarged extraocular muscles showed a diminution in muscle size. We suggest that generalised ophthalmoplegia in carotid cavernous sinus fistula is due to hypoxic, congested extraocular muscles. Isolated abduction weakness is due to a sixth nerve palsy, which probably occurs either in the cavernous sinus or more posteriorly near the inferior petrosal sinus. A combination of these 2 mechanisms may be found in some patients.

A caroticocavernous fistula (CCF) results from abnormal communications between the carotid arterial system and the cavernous sinus. The combination of reduced arterial perfusion and raised venous pressure creates a unique example of orbital and ocular hypoxia, with accompanying venous congestion. ${ }^{1}$

CCF are of 2 types, direct and dural. Direct fistulae are caused by tears in the intracavernous portion of the internal carotid artery arising either from trauma (often severe) or possibly from rupture of a preexisting aneurysm; they usually lie anteriorly in the cavernous sinus ${ }^{2}$ and drain forwards into the orbit. They are high-flow fistulae; the onset of symptoms may be dramatic with severe pulsatile proptosis, bruit, and poor vision due to ocular hypoxia.

Dural fistulae occur when meningeal branches of the internal or external carotid arteries rupture within the cavernous sinus. These vessels are thin walled ${ }^{2}$ and may rupture spontaneously-especially in the hypertensive patient-after minor trauma or on straining. Dural fistulae often lie in the posterior cavernous sinus ${ }^{3}$ and drain backwards into the inferior petrosal sinus. Since they are low-flow fistulae $e^{4}$ the clinical presentation may be subtle, with mild proptosis, redness, and ocular hypertension. Horizontal diplopia due to an ipsilateral weakness of

Correspondence to Mr M. D. Sanders, Department of NeuroOphthalmology, National Hospital for Nervous Diseases, Queen Square, London WC1N 3BG. abduction is common and may herald the other symptoms and signs. ${ }^{3}$

Diplopia is a common symptom in patients with CCF. Approximately one-half of patients with CCF have VI nerve palsies, but the incidence of III and IV nerve palsies varies considerably.

Moseley and Sanders ${ }^{5}$ illustrated a case of ophthalmoplegia due to a CCF and emphasised the associated swelling of extraocular muscles, shown by CT. After spontaneous closure of the fistula the ophthalmoplegia improved rapidly, accompanied by diminution of the extraocular muscle swelling. It was therefore suggested that the swollen muscles contributed to the ophthalmoplegia.

The aim of this paper is to evaluate the aetiology of the ophthalmoplegia in CCF. The clinical findings have been correlated with the angiographic and orbital CT appearances.

\section{Patients}

Fifteen patients with CCF were studied. Seven patients (of whom 3 had suffered a severe head injury) had direct CCF, and 8 had dural fistulae of spontaneous onset.

\section{Results}

Incidence of important clinical findings at presentation. (1) Chemosis and redness $100 \%$, (2) Proptosis $100 \%$, 
(3) Ophthalmoplegia 95\%, (4) Subjective bruit 70\%, (5) Reduced visual acuity $50 \%$, (6) Posterior segment changes $50 \%$, (7) Raised intraocular pressure $21 \%$, (8) Anterior segment ischaemia $20 \%$.

Ophthalmoplegia and CT scan appearances. Fourteen patients had ophthalmoplegia. In 10 of them ocular movements improved after closure of the fistula. The clinical findings when correlated with the orbital CT appearances and pattern of recovery allowed a division of these 10 patients into 3 groups. The 4 patients who did not recover normal eye movements were placed in a separate category.

Group I. Four patients showed an isolated abduction weakness with muscles of normal size on CT and a delayed recovery of the ophthalmoplegia following closure of the fistula (Table 1).

Group II. In contrast, these 4 patients had a generalised ophthalmoplegia with enlarged extraocular muscles on CT and a rapid recovery of ocular movements after closure of the fistula (Table 2).

Group III. Two patients had a generalised ophthalmoplegia with enlarged muscles on CT but differed from those in group II by showing a biphasic recovery of ocular movements after closure of the fistula. Vertical movements and adduction recovered quickly accompanied by a diminution in extraocular muscle size on CT scan. However, the abduction weakness persisted for 3 months (Table 3 ).
Group $I V$. Four patients showed no improvement in the ophthalmoplegia after closure of the fistula, although several of the other symptoms and signs regressed (Table 4). One patient had no evidence of ophthalmoplegia associated with her direct fistula. Her symptoms of a bruit and a dull ache in the eye accompanied by signs of chemosis, redness, and proptosis all resolved rapidly following embolisation of the fistula.

The presentation and natural history of groups I, II, and III is illustrated by a typical patient from each group. Each patient in group IV is briefly described, since there were different factors leading to their failure of treatment.

GROUP I (4 PATIENTS)

Isolated abduction failure. Normal size extraocular muscles on CT. Delayed recovery of abduction following closure of the fistula (Table 1)

Case 1. A 67-year-old woman presented with horizontal diplopia, redness of the right eye, and blurring of the right eye vision. There was no bruit; visual acuity was $6 / 9$ N5 right and 6/6 N5 left. The right eye showed $3 \mathrm{~mm}$ of proptosis with chemosis and redness but was otherwise normal; ocular movements were full except for complete failure of abduction on the right. Orbital CT showed extra-

Table 1 Isolated abduction failure

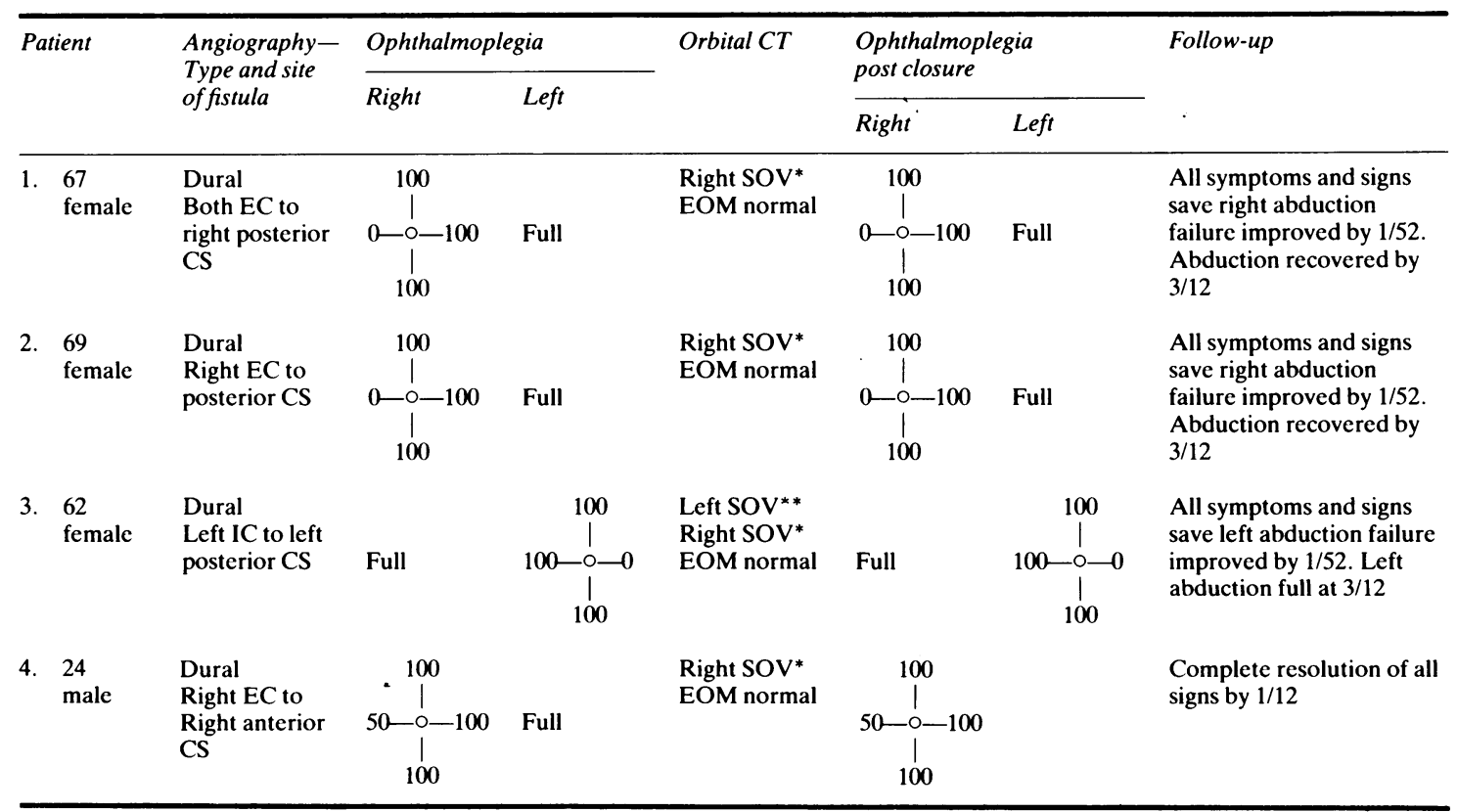

IC=Internal carotid. EC=External carotid. EOM=Extraocular muscles. SOV=Superior ophthalmic vein. CS=Cavernous sinus. ${ }^{* *}$ Very swollen. ${ }^{*}$ Swollen. 
Table 2 Ophthalmoplegia with swollen extraocular muscles. Complete and rapid recovery following closure of the fistula

\begin{tabular}{|c|c|c|c|c|c|c|c|}
\hline \multicolumn{2}{|c|}{ Patient } & \multirow{3}{*}{$\begin{array}{l}\text { Angiography } \\
\begin{array}{l}\text { Direct fistula } \\
\text { Right IC to right } \\
\text { anterior CS }\end{array}\end{array}$} & \multicolumn{2}{|c|}{ Ophthalmoplegia } & \multirow[t]{2}{*}{ Orbital CT } & \multirow[t]{2}{*}{ Follow-up } & \multirow{2}{*}{$\begin{array}{l}\text { Post closure } \\
\text { CT }\end{array}$} \\
\hline & & & Right & Left & & & \\
\hline & $\begin{array}{l}73 \\
\text { male }\end{array}$ & & Nil & Full & $\begin{array}{l}\text { Right } \mathrm{EOM}^{* *} \\
\text { Right SOV** }\end{array}$ & $\begin{array}{l}\text { Balloon embolisation. } \\
\text { All signs resolved by } 1 / 52\end{array}$ & Normal at $1 / 52$ \\
\hline 6. & $\begin{array}{l}47 \\
\text { male }\end{array}$ & $\begin{array}{l}\text { Dural } \\
\text { Left IC to right } \\
\text { anterior CS }\end{array}$ & $\stackrel{\substack{\mid \\
20-0-20 \\
50}}{10}$ & Full & $\begin{array}{l}\text { Right } \text { EOM }^{* *} \\
\text { SOV** }\end{array}$ & $\begin{array}{l}\text { Spontaneous resolution. } \\
\text { All signs regressed by } 1 / 52\end{array}$ & Normal at $1 / 52$ \\
\hline 7. & $\begin{array}{l}67 \\
\text { female }\end{array}$ & $\begin{array}{l}\text { Dural } \\
\text { Left IC to right } \\
\text { anterior CS }\end{array}$ & $\left.{ }_{5}^{1}\right|_{5} ^{5}-5$ & Full & $\begin{array}{r}\text { Right } \mathrm{SOV}^{* *} \\
\mathrm{EOM}^{* *}\end{array}$ & $\begin{array}{l}\text { Spontaneous resolution } \\
\text { after angiography. } \\
\text { All signs regressed } \\
\text { 1/52 after angiogram }\end{array}$ & Not done \\
\hline 8. & $\begin{array}{l}21 \\
\text { male }\end{array}$ & $\begin{array}{l}\text { Direct } \\
\text { Right IC to right } \\
\text { CS }\end{array}$ & $\begin{array}{c}5 \\
90-0-20 \\
1 \\
60\end{array}$ & Full & $\begin{array}{l}\text { Right SOV* } \\
\text { Right EOM* }\end{array}$ & $\begin{array}{l}\text { Failed embolisation. } \\
\text { Spontaneous resolution } \\
2 / 12 \text { later. All signs } \\
\text { including ophthalmoplegia } \\
\text { resolved by } 1 / 52\end{array}$ & Not done \\
\hline
\end{tabular}

Abbreviations and symbols as in Table 1.

ocular muscles of normal size and enlargement of the right superior ophthalmic vein. Carotid angiography demonstrated a right dural fistula supplied by both external carotid arteries via the middle meningeal and ascending pharyngeal branches. Drainage was from the posterior aspect of the right cavernous sinus. Embolisation by balloon was effective in causing regression of all ocular signs except the right abduction weakness, which required 3 months to recover.

GROUP II (4 PATIENTS)

Generalised ophthalmoplegia. Enlarged extraocular muscles on CT. Rapid, complete recovery of eye movements following closure of the fistula. (Table 2)
Case 5. A 73-year-old man developed right-sided bruit and poor visual acuity, three days after severe head trauma. The left eye was normal on examination, but the right eye was red with chemosis and 3 $\mathrm{mm}$ of proptosis. He had a complete right ophthalmoplegia without ptosis. Intraocular pressure in the right eye was normal in the primary position but rose by $8 \mathrm{~mm}$ on attempted upgraze, indicating tethering. Carotid angiography demonstrated a direct $\mathrm{CCF}$ from the right internal carotid artery to the anterior cavernous sinus, while orbital CT showed gross swelling of the extraocular muscles with an enlarged superior ophthalmic vein. Balloon embolisation effected complete cure within one week, including a

Table 3 Ophthalmoplegia with swollen muscles and biphasic recovery. (1) Rapid recovery of all movements save abduction. (2) Delayed recovery of abduction

\begin{tabular}{|c|c|c|c|c|c|}
\hline \multirow[t]{2}{*}{ Patient } & \multirow[t]{2}{*}{ Angiography } & \multicolumn{2}{|c|}{ Ophthalmoplegia } & \multirow[t]{2}{*}{ Orbital CT } & \multirow[t]{2}{*}{ Follow-up } \\
\hline & & Right & Left & & \\
\hline $\begin{array}{ll}\text { 9. } & 56 \\
& \text { female }\end{array}$ & $\begin{array}{l}\text { Direct } \\
\text { Left IC to left anterior } \\
\text { CS and right CS }\end{array}$ & $\left.\right|_{5} ^{5}$ & $\begin{array}{l}\text { Ptosis } \\
\text { Nil } \\
\text {. }\end{array}$ & $\begin{array}{c}\text { Right } \mathrm{EOM}^{* *} \\
\mathrm{SOV}^{* *} \\
\text { Left } \mathrm{EOM}^{* *} \\
\mathrm{SOV}^{* *}\end{array}$ & $\begin{array}{l}\text { Balloon embolisation via left IC. All } \\
\text { signs including ptosis and EOM } \\
\text { recovered in } 1 / 52 \text { except bilateral } \\
\text { abduction failure left >right. Right } \\
\text { recovered } 1 / 12 \text {, left recovered } 3 / 12\end{array}$ \\
\hline 10. $\begin{array}{l}72 \\
\text { female }\end{array}$ & No angiogram & $\left.\left.\right|_{80} ^{70}\right|_{0} ^{2}-80$ & Full & $\begin{array}{l}\text { Right SOV* } \\
\text { Right EOM }{ }^{* *}\end{array}$ & $\begin{array}{l}\text { Spontaneous closure after } 3 / 52 \text {. All } \\
\text { symptoms and signs regressed save } \\
\text { diplopia and recovery of right } \\
\text { abduction. Post closure scan showed } \\
\text { muscle shrinkage }\end{array}$ \\
\hline
\end{tabular}

Abbreviations and symbols as in Table 1. 
return of vision to $6 / 9$ and recovery of full ocular movements. The right intraocular pressure no longer showed a rise on elevation of the eye.

\section{GROUP III (2 PATIENTS)}

Mixed. Generalised ophthalmoplegia. Enlarged extraocular muscles on CT. Rapid recovery of all eye movements except abduction following closure of the fistula. (Table 3)

Case 9. A 56-year-old female with no history of trauma presented with a short history of diplopia, bruit, and redness of both eyes; there was bilateral symmetrical proptosis. Vision on admission was $6 / 5$ N5 in each eye. Ocular movements were grossly restricted bilaterally and she had a left ptosis (Figs. $1 \mathrm{~A}, 1 \mathrm{C})$; the pupillary reactions were entirely normal. CT showed swelling of extraocular muscles in both orbits and enlargement of both superior ophthalmic veins. Carotid angiography demonstrated a direct fistula feeding from the left internal

Figs. 1A, B, C, D Case 9. Bilateral signs from left unilateral CCF. To show rapid regression of signs save left abduction failure after embolisation of fistula by balloon.

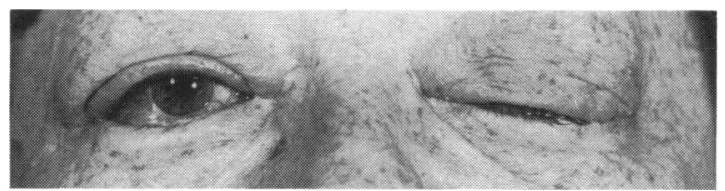

Fig. 1A: Pre-embolisation. Note left ptosis.

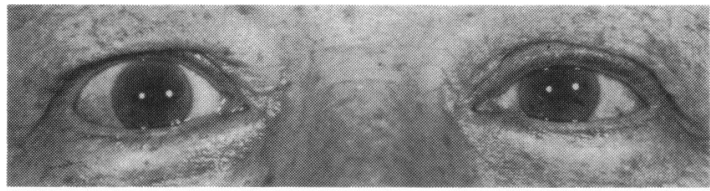

Fig. 1B: One week post embolisation left ptosis resolved.

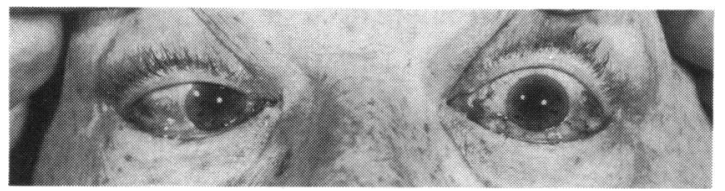

Fig. 1C Pre-embolisation. Attempted left gaze. Note incomplete right adduction and absent left abduction. Bilateral conjunctival injection is also shown.

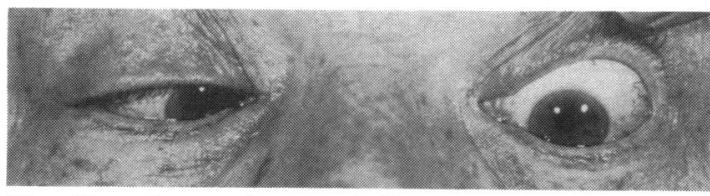

Fig. 1D: Oneweek post embolisation. Attempted left gaze. Note full right adduction but absent left abduction persists. The bilateral conjunctival injection has improved. carotid artery to the left cavernous sinus and, via the intercavernous plexus, to the right anterior cavernous sinus.

Embolisation was carried out by detachable balloon catheter via the left internal carotid artery. Within 5 days the bruit, chemosis, and proptosis had disappeared, and considerable recovery of ocular movement was evident with regression of the ptosis (Figs. 1B, 1D). Although vertical eye movements and adduction were generally much improved after 3 days, and had returned to normal in 2 weeks, the failure of left abduction persisted and did not recover for 3 months.

GROUP IV (4 PATIENTS)

No recovery of ophthalmoplegia

Table 4 illustrates the patients whose eye movements failed to recover. Patient II had an aberrant trigeminal artery which continued to supply the fistula despite embolisation of the internal carotid. The bruit disappeared, but the other signs remained. Patient 12 could not be embolised owing to her haemophilia. Her bruit eventually ceased, but the proptosis and ophthalmoplegia remained. The fistula in case 13 was unusually anterior, draining almost directly via small vessels into the superior ophthalmic vein, and was considered inaccessible to embolisation. CT showed marked proptosis, enlarged superior ophthalmic vein, and enormous extraocular muscles. This unfortunate patient rapidly developed ocular ischaemia with poor vision.

Case 14 was unusual in that a direct fistula resulted from the rupture of an intracavernous aneurysm. Gradual compression of the cranial nerves in the cavernous sinus had resulted in a complete ophthalmoplegia with a diminished corneal reflex. Embolisation eliminated the bruit but the ophthalmoplegia did not improve.

\section{Discussion}

Previous reviews of $\mathrm{CCF}^{6-9}$ have drawn attention to the incidence of ocular motor nerve palsies with VI nerve involvement occurring in approximately onehalf of all patients. There is less agreement on the frequency with which III and IV nerve palsies are found.

The diagnosis of III and IV nerve palsies in congested orbits may be very difficult. Although III nerve involvement may be associated with ptosis or an afferent pupillary defect, a mechanical ptosis is often found in inflamed eyes, and in many cases of $\mathrm{CCF}$ the iris becomes ischaemic, making interpretation of the pupillary signs unreliable.

Our findings suggest that many patients do have VI nerve palsies, but that the other ocular motor problems are due to swollen extraocular muscles. The 
Table 4 No recovery of ophthalmoplegia

\begin{tabular}{|c|c|c|c|c|c|c|}
\hline \multirow{2}{*}{\multicolumn{2}{|c|}{ Patient }} & \multirow[t]{2}{*}{ Angiogram } & \multicolumn{2}{|c|}{ Ophthalmoplegia } & \multirow[t]{2}{*}{$C T$} & \multirow[t]{2}{*}{ Follow-up } \\
\hline & & & Right & Left & & \\
\hline 11. & $\begin{array}{l}31 \\
\text { male }\end{array}$ & $\begin{array}{l}\text { Direct } \\
\text { Left IC to left CS. Also } \\
\text { supplied from aberrent } \\
\text { trigeminal artery }\end{array}$ & Full & Nil & $\begin{array}{l}\text { Left SOV** } \\
\text { EOM }^{* *}\end{array}$ & $\begin{array}{l}\text { Embolisation removed bruit but all } \\
\text { other signs remained. CCF continued to } \\
\text { be fed from trigeminal artery }\end{array}$ \\
\hline 12. & $\begin{array}{l}29 \\
\text { female }\end{array}$ & $\begin{array}{l}\text { Direct } \\
\text { Left IC to right anterior } \\
\text { CS and left CS }\end{array}$ & Nil & Full & $\begin{array}{l}\text { Right } \text { SOV }^{* *} \\
\text { EOM** }^{* *} \\
\text { Left SOV** }\end{array}$ & $\begin{array}{l}\text { Patient had haemophilia. Bruit } \\
\text { gradually regressed. Other signs } \\
\text { unchanged at } 1 \text { year }\end{array}$ \\
\hline 13. & $\begin{array}{l}56 \\
\text { female }\end{array}$ & $\begin{array}{l}\text { Dural from left IC to } \\
\text { left anterior CS and } \\
\text { left SOV }\end{array}$ & Full & Nil & $\begin{array}{l}\text { Left } \text { EOM }^{* *} \\
\text { SOV }^{* *}\end{array}$ & $\begin{array}{l}\text { Dural vessels not possible to embolise. } \\
\text { All signs unchanged at } 6 / 12\end{array}$ \\
\hline & $\begin{array}{l}84 \\
\text { female }\end{array}$ & $\begin{array}{l}\text { Direct } \\
\text { ? rupture of right } \\
\text { intracavernous IC } \\
\text { aneurysm into right } \\
\text { CS }\end{array}$ & Nil & Full & $\begin{array}{c}\text { Right } \text { EOM }^{* *} \\
\text { SOV }^{* *}\end{array}$ & $\begin{array}{l}\text { Symptoms signs for } 1 \text { year. Embolised. } \\
\text { Bruit eliminated. All other signs } \\
\text { unchanged at } 6 / 12\end{array}$ \\
\hline
\end{tabular}

Abbreviations and symbols as in Table 1.

different mechanisms can be determined by correlation of the physical signs, angiography, and orbital CT.

Isolated abduction weakness was the only ocular motor problem in cases $1-4$, in whom CT demonstrated extraocular muscles of normal size. There was no evidence of orbital or ocular ischaemia, and the III, IV, and V nerves were uninvolved. Carotid angiography demonstrated the site of the fistula to be posterior in cases 1,2 , and 3 but anterior in case 4 .

Abduction completely recovered in each patient but required from one month (case 4) to 3 months (cases 1-3). This slow recovery, in the absence of swollen muscles, involvement of other cranial nerves, or orbital ischaemia, suggests that these patients had suffered a VI nerve palsy posterior to the superior orbital fissure. The probable site of damage was either posteriorly where the VI nerve passes beneath the petroclinoid ligament near the inferior petrosal sinus or in the cavernous sinus.

Newton and Hoyt ${ }^{3}$ commented on the frequent posterior location of the dural fistulae within the cavernous sinus. Posterior fistulae may drain into the inferior petrosal sinus, causing distension of the sinus and intermittent compression of the VI nerve. ${ }^{3}$ This would explain the characteristic transient horizontal diplopia which may herald the other symptoms and signs in dural fistulae. Compression of the nerve against the petroclinoid ligament or interruption of the fragile arterial blood supply would cause a VI nerve palsy.

The IV nerve enters the cavernous sinus posteriorly either in or contiguous to the inferior petrosal sinus. ${ }^{23}$ Usually it lies immediately lateral to the internal carotid artery, surrounded by a separate sheath, but it may be adherent to the lateral wall of the artery. In the posterior part of the cavernous sinus the blood supply to the VI nerve is from the dorsomeningeal branch of the internal carotid artery.

There are therefore 2 potential sites for damage to the VI nerve within the cavernous sinus. A direct fistula could involve the closely related internal carotid artery or a dural fistula feeding from the dorsomeningeal branch might jeopardise the blood supply of the nerve.

In this series the 4 patients thought to have VI nerve palsies had dural fistulae confirmed by carotid angiography. Three months was required in each patient for recovery of abduction. In contrast, case 4 had an anteriorly placed fistula, and abduction improved within a month of closure.

The 4 patients with a generalised ophthalmoplegia and swollen extraocular muscles on orbital CT had a different mechanism for their reduced eye movements from the cases in group I. Each patient showed a rapid recovery of normal eye movements after closure of the fistula accompanied by a diminution of extraocular muscle swelling on the orbital CT.

Each patient in group II had a bruit. The sudden elimination of the bruit, either following embolisation or spontaneous cure, was used as a guide to determine the time of closure of the fistula.

On closure of the fistula the bruit in case 5 ceased immediately and the ophthalmoplegia resolved within one week. In case 6 the fistula appeared to close spontaneously, as shown by cessation of the bruit and 
loss of the persistent ache within the eye. The eye movements improved within a week, and the improvement was accompanied by a diminution in ocular muscle swelling on orbital CT scan.

In cases 7 and 8 the fistula closed after invasive procedures, angiography in case 7 and attempted embolisation in case 8. Again the ophthalmoplegia improved rapidly in each patient after a sudden cessation of the bruit.

Anteriorly placed fistulae tend to drain into the orbit. ${ }^{2}$ This applies to both direct fistulae (case 5) and dural fistulae (cases 6 and 7). A narrowing of arteriovenous pressure gradient occurs within the orbit ${ }^{1}$ leading to orbital hypoxia and venous congestion. The extraocular muscles may become extremely swollen, often trebling their usual size, with consequent mechanical interference with normal function like that seen in dysthyroid eye disease. Tamponade of the globe may raise the intraocular pressure, especially on attempted upgaze, emphasising the restrictive component of the ophthalmoplegia as shown in case 5 .

The rapid recovery of extraocular muscle function following closure of the fistula was associated with a diminution in extraocular muscle size. This recovery occurred despite the ophthalmoplegia having been present for several months in some cases. If the mechanism of the ophthalmoplegia were purely ischaemic, then such a rapid and complete recovery would be unlikely. There was little evidence of III and IV nerve dysfunction, though ischaemia to the ocular motor nerves within the orbit might be implicated as a possible cause of the ophthalmoplegia. However, the corneal reflex, usually a sensitive indicator of compression or ischaemic insult at the orbital apex, remained intact in all the patients shown in Table 2. None had evidence of anterior segment ischaemia, and pupil reactions were normal in each case.

The 2 patients in group III showed a combination of the mechanisms so far identified as causing ophthalmoplegia in CCF. Case 9 as detailed above illustrated a severe bilateral ophthalmoplegia due to a unilateral direct fistula. Grossly swollen extraocular muscles could be demonstrated on CT scan, and angiography confirmed the site of the fistula in the left anterior cavernous sinus.

Balloon embolisation effected complete cure of the symptoms and signs of the fistula, except the ophthalmoplegia, within one week. Although the ptosis, vertical eye movement, and adduction recovered quickly, a return of full abduction was delayed.

The patient reported as case 10 similarly showed resolution of the generalised ophthalmoplegia except for abduction following spontaneous closure of the

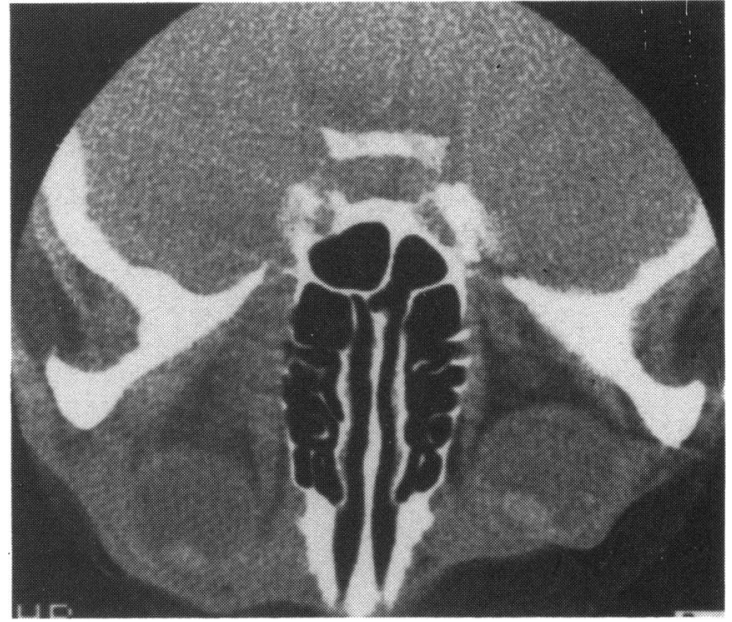

Fig. 2A Case 10. Preclosure orbital scan to show swollen extraocular muscles in right orbit.

fistula. The orbital scans (Figs. 2A, 2B) illustrate the diminution in extraocular muscle swelling and also the failure of abduction (Fig. 2B).

In conclusion, we suggest different aetiologies for the ophthalmoplegia in a series of patients with CCF. Analysis of the clinical signs, the results of investigations, and recovery after cure indicate that isolated abduction failure without CT evidence of ocular muscle swelling is due to a VI nerve palsy, while a generalised ophthalmoplegia is caused by mechanical restriction from swollen ocular muscles.

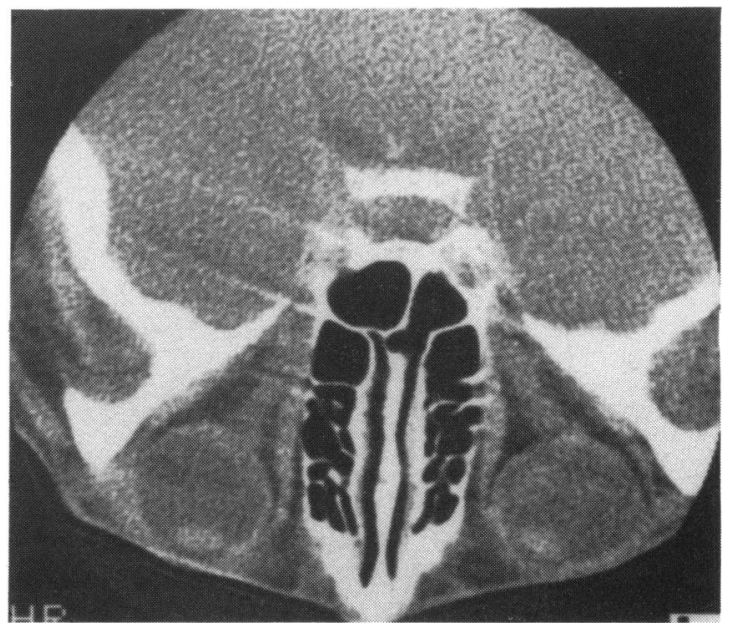

Fig. 2B One week post closure orbital scan taken with eyes in attempted dextroversion (see position of the lens in each eye). While the left eye performs normal adduction, the right eye cannot abduct despite reduction in extraocular muscle size. 


\section{References}

1 Sanders MD, Hoyt WF. Hypoxic sequelae of carotid cavernous fistulae. Br J Ophthalmol 1969; 53: 82-97.

2 Parkinson D. A surgical approach to the cavernous portion of the carotid artery. Can J Surg 1964; 7: 251-68.

3 Newton T, Hoyt W. Dural arteriovenous shunts in the region of the cavernous sinus. Neuroradiology 1970; 1: 71-81.

4 Hayes GJ. External carotid-cavernous fistulae. J Neurosurg 1963; 20: $692-700$.
5 Moseley IF, Sanders MD. Computerised tomography in neuroophthalmology. London: Chapman and Hall, 1982: 67.

6 Henderson JW, Schreider RC. Ocular findings in carotid cavernous fistula. Am J Ophthalmol 1959; 48: 585-91.

7 Madsen PH. Carotid cavernous fistula. Acta Ophthalmol (Kbh) 1970; 48: 731-7.

8 Odom GL. Ophthalmic involvement in neurological vascular lesions. In: Smith JL, ed. Neuro-ophthalmology. Springfield: Thomas, 1964: 1: 181.

9 Palestine AG, Younge B, Diepgmas D. Visual prognosis in carotid cavernous fistula. Arch Ophthalmol 1981; 99: 1600-3. 